\title{
Water industry: water-energy-health nexus
}

\author{
Hyunwoong Park ${ }^{1}$ (1) $\cdot$ Woong Kim ${ }^{2}$
}

Received: 5 October 2018 / Accepted: 17 October 2018 / Published online: 22 October 2018

(C) Springer-Verlag GmbH Germany, part of Springer Nature 2018

Water, energy, and human health have very close relationships. Energy requires a significant amount of water in the production, purification, and distribution processes, whereas the supply of energy to the purification and transport of water is essential. Most of the water contaminated with pathogens from human/animal feces causes diseases including diarrhea. Unfortunately, residents in areas that are not receiving a stable supply of energy and where access to safe and clean drinking water is restricted, especially young children under the age of five, are more likely to be exposed to various bacteria and live in less sanitary environments. In this regard, energy-efficient water treatment technologies are urgently needed for sustainable, healthy human living.

The International Water Industry Conference 2016, organized by Kyungpook National University (KNU) Advanced Institute of Water Industry, Daegu, Korea, 18-21 October, 2016, was held to share and discuss recent research activities with water industry in terms of water-energy-health. The water-energy-health nexus issue is one of the most important and urgent subjects to be resolved for both the current and next generations. Selected papers on innovative topics on the nexus, including photocatalytic water treatment, aerobic and anaerobic microbial reactions, electrocatalysis, sonolysis, and membrane osmosis, are published in this special issue. The editors of the special issue acknowledge the support from the National Research Foundation of Korea (2016R1A2B4007366 and 2018R1A6A1A03024962), the city of Daegu, and the Korea Tourism Office. In addition, we are grateful to Prof. Kwang-Ho Choo at the Department of Environmental Engineering, KNU, for his sincere support as a chairperson of the Conference.

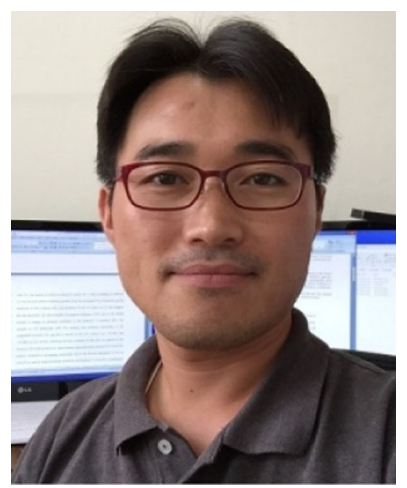

Prof. Hyunwoong Park received a B.S. in Environmental Science at Hallym University in 1999 and a $\mathrm{Ph} . \mathrm{D}$. degree in Environmental Engineering at POSTECH (Pohang, Korea) in 2004. After postdoctoral research at the California Institute of Technology (Pasadena, CA: 2006-2008), he moved to the School of Energy Engineering at Kyungpook National University (Daegu, Korea) as an assistant professor (2008) and was then promoted to associate (2012) and full (2017) professor. He has published over 140 papers in peer-reviewed journals, which have been cited over 8200 times. He received the Knowledge Creativity Award by the Ministry of Education, Science, and Technology, Korea (2012), and the Best Paper Award by the Korean Electrochemical Society (KEC, 2013), the SBS Foundation Fellowship (2014), the KEC Park Su-Mun Award (2018), and the Kyungpook National University Academy Award (2018). He is serving as the Editor of Materials Science in Semiconductor Processing (Elsevier, since 2015) and the Associate Editor of Environmental Engineering Research (Korean Society of Environmental Engineers, since 2014), and on the editorial advisory boards of Journal of Environmental Chemical Engineering (Elsevier, since 2013). He has also served as a Guest Editor of Catalysis Today (Vol. 282, Elsevier) and International Journal of Photoenergy (Hindawi, 2014).

Responsible editor: Philippe Garrigues

Hyunwoong Park

hwp@knu.ac.kr

1 School of Energy Engineering, Kyungpook National University, Daegu 41566, South Korea

2 Department of Environmental Engineering, Kyungpook National University, Daegu 41566, South Korea 


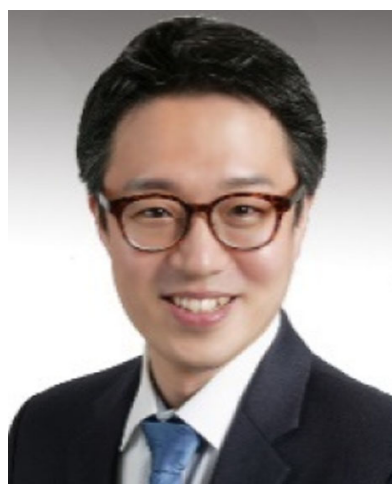

Woong Kim received a B.S. in Animal Science/Technology and Microbiology at Seoul National University in 1996 and a Master and a Ph.D. degree in Environmental Engineering at POSTECH (Pohang, South Korea) in 1998 and 2011, respectively. After his staying as a postdoctoral fellow and research assistant professor at the Institute of Environmental \& Energy Technology (POSTECH: 20112012) and the Department of Biomolecular Chemical

Engineering (KAIST: 2013-2015), respectively, he moved to the
Department of Environmental Engineering at Kyungpook National University (Daegu, South Korea) as an assistant professor (2015). He has published over 60 papers in peer-reviewed journals and received the Best Paper Award and Best Oral Presentation Award by the Korean Society of Environmental Engineers (2014). He was a consultant of NAVER (South Korea) for the construction of eco-friendly buildings, and also of Chungnam Metropolitan Gas Agency for the remodeling of gas plants. He is serving as the Editor of Microbiology and Biotechnology Letters (since 2018). In addition, he has served as a Science and Creativity Ambassador (The Korea Foundation for the Advancement of Science and Creativity: 2013-2014). 